\title{
Deficiencies and loopholes: clashing discourses, problems and solutions in Australian migration advice regulation
}

\author{
Laura Smith-Khan
}

Accepted version, 26 February 2021. The published version is 'Deficiencies and loopholes: Clashing discourses, problems and solutions in Australian migration advice regulation,' Discourse and Society, 2021, 32, (5), pp. 598-621, 


\begin{abstract}
In Australia, access to high-quality migration advice can often be crucial to obtaining a visa, and migration advisors have attracted ongoing scrutiny from policymakers, leading to successive inquiries and reviews. Such inquiries and the recommendations they produce are used to justify policy design and reform that can have significant impacts on a range of stakeholders, including of course, migration advisors and their clients. This article explores one such recent inquiry, completed in 2018. It adopts a critical discourse analysis to examine the way the inquiry's official report presents migration advisors, and how it frames the inquiry process itself. Finding that the report presents its recommendations as being based on evidence created by external stakeholder submissions, the examination goes on to explore to what extent this is actually the case. Through an examination of the "textual travels" submissions undergo when incorporated in the report, the article finds that these texts are either transformed to support dominant discourses, or simply excluded. The article concludes that decision-making is inaccurately presented as a participatory, evidence-based process, thus legitimizing particular policy decisions, and unfairly continuing to present migration advisors as problems requiring fixing.
\end{abstract}

\title{
Keywords
}

Migration, policy, law, migration advice, regulation, legal-lay communication, textual travels, entextualization, critical discourse analysis, evidence-based policymaking, social actor analysis, Australia, parliamentary inquiry, government decision-making, legal practice, law and language 


\section{Biography}

Dr Laura Smith-Khan is a Chancellor's Postdoctoral Research Fellow in the Faculty of Law at the University of Technology Sydney (UTS). Her current project explores the regulation, practice and education of Australian migration advisors. She is co-founder of the Law and Linguistics Interdisciplinary Researchers' Network. Dr Smith-Khan's doctoral research examined credibility, language and communication in Australia's refugee policy, procedures and public discourse and was conducted under joint supervision in Linguistics and Law at Macquarie University. She has published and presented her research across a number of media, both in Australia and overseas, and regularly shares her work via www.languageonthemove.com.

\section{Acknowledgements}

The research for and preparation of this article were made possible thanks to a UTS Chancellor's Postdoctoral Research Fellowship. Thanks to Dr Alyssa Severin for her research assistance in the early stages of data collection and analysis. As always, I'm grateful for the feedback and encouragement of my Language on the Move research group peers, and to my UTS Law colleagues. 


\section{Introduction}

In Australia, migration is a highly politicized and constantly evolving area of the law. Similarly, registered migration agents (RMAs), the professionals authorised to assist people with their visa applications, attract ongoing scrutiny in political and media discourse (Khan, 2019). This includes high-level government officials accusing lawyers and advocates of trying to undermine entry bars to achieve "migration outcomes" for their clients (Smith-Khan, 2019a, 2019b).

This scrutiny has engendered successive official reviews and inquiries into the regulation of the profession. These activities and their outcomes are important as they are used to justify law and policy related to RMAs' qualifications and practice. However, existing research on Australian policymaking has problematized inquiry processes, identifying inconsistent reasoning, and questioning the extent to which policymakers actually rely on the evidence they collect when designing policy. The findings suggest that a primary purpose of such inquiries is to create and emphasise particular "social problems" that need fixing (Van Toorn and Dowse, 2016: 9).

This article takes up these contentions to examine a recent inquiry into RMA regulation, exploring the collection of publicly available documents constituting it: an official website, transcripts of public hearings, written submissions from various stakeholders and an official report. Using critical discourse analysis (CDA), it explores discourse creation on two levels. It examines how the report presents the inquiry process and its participants. It also explores control over discourse relating to the subject matter of the inquiry, RMA regulation, by examining dominant institutional discourse, and the "textual travels" of the stakeholders' submissions from their origins, to their inclusion in the report (Heffer et al., 2013).

The article demonstrates how the inquiry's report presents the process as one of objectively considering stakeholder submissions, which become evidence used to arrive logically at a set of conclusions and recommendations. However, while pieces of evidence are presented as "circulable texts" (Park and Bucholtz, 2009: 486) belonging to submitters, the analysis demonstrates the diverse ways in which the report transforms them to align with institutional discourse. The examination of these texts' travels is thus used to challenge the report's presentation of the inquiry process.

Below, Section 2 introduces the study's theoretical and methodological framework. Section 3 provides some background on Australian migration practice, and describes the inquiry and 
the various texts that constitute it. It also examines institutional discourse about migration and RMA regulation, especially as presented in the Terms of Reference (TORs). Section 4 explores how the report discursively presents the inquiry process and its participants. Complementing Section 3, Section 5 examines submitters' discourse, tracing textual travel within the inquiry, and exploring how submissions that challenge the inquiry's TORs and dominant discourses are transformed. Reflecting on the preceding analysis, Section 6 discusses submitters' attempts to critique the inquiry, and reflects on power and control over both discourses within and discourses about the inquiry. Section 7 summarizes the article's contributions to existing scholarship, and implications for RMA-related policymaking.

\section{Methodology and data}

Evidence-based, participatory policymaking is a relatively new concept in Australia. Van Toorn and Dowse (2016) critically examine evidence-based policymaking in two Australian policy documents to demonstrate how evidence is selectively cited and interpreted to frame certain social phenomena as problems, and to justify particular policy in response. They identify examples of how evidence is misrepresented and/or "used strategically rather than systematically in an attempt to undermine contending arguments" (17). They conclude that rather than driving policy, "evidence operates as a discursive tool for consolidation of particular frames and problem representations" (20).

The current article builds on these findings by critically examining the ways in which texts are mobilized and transformed in the Inquiry into efficacy of current regulation of Australian migration and education agents.

Research in diverse legal settings has demonstrated how texts are transformed across institutional processes. These include, for example, studies where lawyers draw on excerpts from police interviews with defendants, or from earlier witness (cross-)examination, to strategically present evidence in a desired light (e.g. Eades, 2012; Johnson, 2013). They demonstrate how such strategies can mask the author's or speaker's own role in discourse creation: drawing on the evidence of others is a legitimate discursive practice in such settings. For example, Maryns found that lawyers' animating other people's voices 'offer[ed] them the opportunity to ventilate particular ideas and subjectivities without necessarily taking responsibility" for them and thus "as a strategy to shuffle their own preferred interpretations of the facts into the legal space" (Maryns, 2013: 121). Rock et al. (2013: 4), propose the term 
"textual travel" to conceptualize "the way texts move through and around institutional processes and are shaped, altered and appropriated during their journeys".

Adopting this approach to explore the inquiry, the current article traces the "movement" of texts, from their originally-produced forms, throughout the inquiry process. It employs CDA to uncover the "diverse representations of social life" evident in the different inquiry texts (Fairclough, 2001: 123). Importantly, this helps to uncover dominant discourses in a setting where the policy conclusions reached can influence or justify wide-reaching legislation and government practices.

The examination proceeds with the understanding that "discourse constitutes social practice and is at the same time constituted by it" (Van Leeuwen and Wodak, 1999: 92). Therefore it not only explores how different actors and texts represent social realities of the outside world. It is also interested in uncovering the discursive representations of discourse creation within the inquiry process itself. Discourses are a powerful resource that can be used to promote the status quo and thus entrench power, while making invisible or justifying inequality. This is true across all social contexts and practices, including discourse production itself. Therefore, denaturalizing mechanisms of discourse control and reproduction is an essential step in addressing inequality and empowering those whom such discourse negatively affects (Van Dijk, 2008).

Therefore, this article seeks to uncover the discursive representation of the inquiry process and its participants. It then challenges these representations by examining how texts travel through the inquiry process, identifying which ones retain their original underlying discourses, and which are co-opted to support other discourses. It considers who has control over these trajectories, and to what ends. The article thus aims to interrogate the apparently participatory and objective nature of parliamentary inquiries by demonstrating the unequal control over text and discourse throughout these processes.

To achieve this, the study first involved CDA of the inquiry report's TORs, recommendations, structure and third Chapter, which deals most closely with migration agents and their regulation, to uncover institutional discourse about migration regulation and migration advisors (see Section 3.2), and about the inquiry process and its participants (Section 4). It then traced the "textual travels" of 40 written submissions, seven public hearings and other texts cited in Chapter 3 (details available on the inquiry website). This involved systematically mapping, in Microsoft Excel, each paragraph in Chapter 3, noting the original source the report cited for each, and then comparing the chapter paragraph and the original text 
to critically examine how the original was transformed within the report. Counts were also undertaken of how often different stakeholders were cited, and how many raised particular issues or made particular recommendations. CDA of the submissions, especially those from non-government stakeholders, was undertaken to identify themes or issues raised that appeared to conflict with institutional discourses and/or went beyond the "problems" identified by the TORs. This CDA and the comparative analysis then allowed an examination of how counterdiscourses were controlled, transformed and excluded. Below I introduce the policy context, and inquiry TORs.

\section{Migration practice and the Inquiry}

\subsection{Regulating Australian migration}

Individuals wishing to apply for an Australian visa can do so independently. However, the complex and ever-evolving nature of Australian migration law means that professional assistance is often essential. Law restricts who can assist and charge a fee for this work. Currently, only Registered Migration Agents (RMAs) or practicing lawyers are permitted to provide advice or assist individuals making applications to the Department of Home Affairs (DHA), or seeking merits review of negative decisions. At the time of the Inquiry, registration, through the Office of the Migration Agents Registration Authority (OMARA) (within DHA), was possible either by acquiring a legal qualification, or by completing a one-year Graduate Diploma in Migration Law and Practice and passing an external exam. From 2020, practicing lawyers no longer need to register with OMARA. They may also assist migration clients with (higher-level) review in the courts.

Given the politicization of migration, it is perhaps unsurprising that it has attracted ongoing scrutiny by policymakers. The Australian Parliament's Joint Standing Committee on Migration ("the Committee"), whose ten members come from the government's lower and upper houses (MPs and senators respectively) and various political parties (although a majority come from the party in power), regularly conducts inquiries and reviews related to migration law itself, as well as into RMA regulation.

In 2018, the Committee initiated the Inquiry into efficacy of current regulation of Australian migration and education agents ('the inquiry'), issuing its TORs, receiving 41 written submissions from various stakeholders (ranging from one to 80 pages in length), conducting seven public hearings with some of these stakeholders, receiving a eight further written 
submissions from stakeholders in response to other submissions or to hearing queries, and producing a report with a list of recommendations.

\subsection{Institutional discourses about migration regulation}

The TORs guided the written submissions and hearings, as well as the structure of the report. They appear on the inquiry website as follows, and are replicated at the beginning of the report (p. xiii).

\section{Terms of Reference}

The Joint Standing Committee on Migration shall inquire into the efficacy of current regulation of Australian migration agents. In conducting its inquiry, the Committee shall have particular regard to:

- Examining the registration and regulation of migration agents in Australia including: education, English proficiency, payment, fee-scheduling as well as the suitability and stringency of the accreditation process and evidence of deficiencies.

- The nature and prevalence of fraud, professional misconduct and other breaches by registered migration agents, the current review mechanisms for migration agents and the adequacy of penalties.

- Deficiencies and barriers to relevant authorities' investigation of fraudulent behaviour by registered migration agents in visa applications, including the adequacy of information and evidence sharing between such authorities.

- Evidence of the volumes and patterns of unregistered migration agents and education agents providing unlawful immigration services in Australia.

- Reviewing the appropriateness of migration agents providing other services to clients.

- The Joint Standing Committee on Migration shall also separately examine integrity issues associated with the Electronic Travel Authority (subclass 601) visa. The Committee shall have particular regard to evidence of visa cancellation rates, non-compliance with 'no work' conditions, and other integrity concerns (Parliament of Australia, 2018b).

A common concern in the TORs is how to control how RMAs work, their competencies or deficiencies, and addressing criminal behaviour of RMAs or individuals working in related areas. The focus is therefore on this group of individuals and their potential for incompetency and/or criminality, and processes to control and discipline them.

In the report, the Committee recommended government (1) undertake a review of current registration requirements; (2) require new RMAs to complete a period of supervised practice; (3) establish a statutory body to investigate and resolve complaints and sanction unregistered practice, and (4) publish information about RMA pricing arrangements. It made six further recommendations relating to other aspects of the TORs, not focused on RMAs (pp. xv-Xvii). 
The report was tabled in Parliament on 21 February 2019 and as of February 2021, the government has made no response (Parliament of Australia, 2021).

The report is 124 pages long, and is divided into various chapters, beginning with a foreword, details of committee membership, TORs and recommendations. Chapter 2 provides background on RMAs, citing mainly from submissions made by DHA and from other government sources, like the OMARA website. Chapter 3 is the key chapter addressing the TORs regarding RMAs and therefore forms the focus of the current article. It consists of 250 numbered paragraphs and 215 footnoted citations.

The Committee Chair's foreword replicates the discourses evident in the TORs, using strongly emotive language. Its opening sentence adopts a criminality discourse, including terms like "crime”, "illegitimate", “exploit” and "exploiting", "unscrupulous", "unlawful”.

\section{Extract 1}

Loopholes in the law are allowing organised crime and illegitimate labour hire companies to exploit Australia's immigration system and unscrupulous individuals providing unregistered immigration advice, unlawful registered migration agents and education agents are exploiting visa applicants (Report, p. vii).

"Loopholes in the law" suggest the need for stricter regulation. Criminality spans both the behaviour of RMAs and other individuals in similar roles, as well as migrants themselves. This link is developed in the next seven paragraphs, which all speak of the practice of agents assisting "illegal workers" to "exploit" the refugee visa process to remain in the country, through their access to the Electronic Travel Authority system, which allows travellers from certain countries to enter Australia relatively easily. The decision to include this issue within the TORs of an "inquiry into efficacy of current regulation of Australian migration and education agents" adds significant weight to the discourses of criminality that are associated with RMAs.

This issue thus provides the background against which the presumably central focus of the inquiry - given its title - is introduced. The subsequent paragraphs discuss the size of the RMA service "industry" and international student industry (relevant to education agents as well as RMAs) in economic terms.

Clients are then described as coming from "culturally and linguistically diverse backgrounds". Another important discourse is prevalent here: vulnerability. Clients are described as "socially, legally and finically vulnerable and are open to exploitation from the actions of unscrupulous, unlawful and unethical registered migration agents". They are later 
referred to as "victims". This language is evident again in Chapter 3, with a subsection discussing "Vulnerable victims" (p. ix).

The institutional discourse therefore problematizes the actions and motivations of apparently flawed individuals, RMAs, emphasizing the need to protect their clients, who themselves are presented as vulnerable individuals, thereby justifying control through strict regulation.

Against the backdrop of these institutional discourses, the remaining sections will explore how texts and the discourses underlying them are preserved or transformed across the inquiry process. However, to understand how these processes are legitimized, it is first necessary to examine the way in which the inquiry process itself is discursively presented.

\section{The report as a representation of the inquiry process}

While the above CDA demonstrates that the TORs clearly serve to represent particular overwhelming negative - perspectives about RMAs and migrants, their role in the inquiry process may on the surface seem quite benign. Indeed, traditional policy studies have generally conceptualized "problems" as matters of fact, external to policymaking processes. Critical scholars, like Carol Bacchi (2018: 5), challenge this, arguing that rather than simply responding to external realities, governments are "involved in the creation or production of 'problems' as particular sorts of problems, with particular parameters, causes, effects and remedies." Yet, this may be far from evident in how the inquiry process is presented within institutional discourse.

Examining the inquiry report uncovers and challenges institutional representations of the decision-making process. This section thus explores how the report discursively constructs the inquiry process: how the inclusion and framing of submissions and hearings act to present and reinforce a particular understanding of evidence-gathering, participation and decision-making.

Examining immigration officials' rejection letters to prospective migrants, Van Leeuwen and Wodak (1999: 96) explain how the representation of an activity "always involves recontextualization". Thus, in their study, while the rejection letters themselves are not the decision-making process, they offer a representation of this process. Therefore, the analysis in this section considers how the report, as the official, publicly available record, tabled in Parliament, represents the social activity of the inquiry and the participants therein, thereby legitimizing the decisions reached. It thus contributes to addressing the gap identified in Australia policy studies regarding investigating "how groups mobilise around the discourse of 
[evidence-based policymaking] and use it to validate and contest different perspectives" (Van Toorn \& Dowse, 2016: 12).

\subsection{Actors and actions}

Chapter 3 of the report is entitled 'Migration agents' and is said to provide:

...a summary of submitters' views on registered migration agents. It examines the registration requirements of RMAs, the numbers and patterns of unregistered migration agents and education agents providing unlawful immigration services, the power of [OMARA], and considers whether migration agents should provide other services (paragraph 3.1, my emphasis).

Therefore, from the very beginning it claims to present - in part - views belonging to other actors, rather than the Committee's own views (see Figure 1 for the full chapter structure). Simultaneously, repeated use of the definite article suggests it examines various aspects as a matter of fact, presumably based on exploring the submitters' views. Here and throughout, the report author(s) make no reference to themselves, but rather assign agency to "the chapter" or "the report" itself. Where agency is assigned to those involved in report production, it is to "the Committee" as a collective unit. These naming practices are common in legal writing, like court and tribunal decisions. They reinforce the authors' neutrality and background their inherently subjective evaluations (cf Smith-Khan, 2017a, 2017b, 2019c). Using the parliamentary-bestowed title, "the Committee", with capitalization, indexes the actors' official affiliation to legitimate their authority (Smith-Khan, 2019a; Van Leeuwen, 2007).

The attribution of certain parts of the chapter to the submitters is reinforced by embedding excerpts of written submissions and public hearings. Overall, 193 of the 250 paragraphs in Chapter 3 quote or summarise specific submitters' speech or writing, almost always explicitly presenting them as agents, as in Extract 2, below. Assigning the submitters roles like this means they are "represented as the active, dynamic forces in an activity" (Van Leeuwen, 1996: 43). They are thus foregrounded as active inquiry participants in a majority of the chapter's paragraphs.

\section{Extract 2}

The Law Council of Australia were supportive of the qualification requirements stating that:

They provide a stronger basis for the acquisition and assessment of whether a person has a body of knowledge, practical skills and values necessary for effective and ethical practise as an entry-level migration agent (para 3.27). 
Directly naming and quoting individual submitters foregrounds their agency and responsibility for these embedded texts.

A further 13 paragraphs refer to multiple submitters in more general ways, for example:

\section{Extract 3}

Submitters commented on the importance of English language proficiency in understanding complex legislation and representing clients from culturally and linguistically diverse backgrounds (para. 3.30).

In all, 82 percent of the chapter is attributed to various submitters. "The Committee" is assigned authorship of only 38 paragraphs (15\%) in the chapter, including 34 paragraphs of "Committee comments" and four single paragraphs setting out the Committee's first four recommendations.

When framing the Committee's comments and recommendations, and also in the report Foreword, signed by the Committee Chair, the report presents the inquiry as a process of evidence collection. The selective evaluative processes involved in composing the report are backgrounded and "evidence" itself is activated, presenting the conclusions reached as objective. This activation occurs as early as the Foreword: "Evidence to this inquiry showed that..." (Report, p. ix). Similarly, the introductory section describing the inquiry reports:

\section{Extract 11}

The Committee received 41 submissions from a range of federal government departments, refugee and asylum seeker peak bodies, migration lawyers and agents, providers of education services for international students, education agents, and concerned citizens. The Committee took evidence from fifteen organisations and individuals at six public hearings... (Report, para. 1.8, my emphasis).

Extract 11 presents the Committee as passive recipient of something possessed and produced independently by other actors: it received submissions and took evidence. The framing in Chapter 3 is similar. For example, again the Committee is presented as passive recipient: "The Committee received a range of evidence suggesting..." (para. 3.172), "Evidence was received which referred to..." (3.238), "The Committee has not received any direct evidence during this inquiry that would indicate..." (3.248). "Evidence" itself is again activated, verbatim: "Evidence to this inquiry showed that..." (para. 3.219).

This presentation supports an understanding of "evidence" as an external, stable product that itself determines decision-making outcomes. In combination with assigning production and communication roles to the submitters, this activation of evidence minimizes the evaluative processes involved in decision-making. It also makes it appear that submitters and the evidence itself have a great influence on or control over the Committee's comments and 
recommendations. This backgrounds the institutional control over every stage of the inquiry process, as demonstrated further in the coming sections. However, given that these grammatical choices are common to this genre of writing, they may pass largely unnoticed. Other common conventions reinforce this division of roles and are explored below.

\subsection{Generic conventions}

Chapter structure and citation practices in the report align with other inquiry reports, and resemble other types of legal writing in their referencing style and paragraph numbering. Figure 1 sets out the organization of Chapter 3. There are well-delineated separate sections, each with its own heading and paragraph numbers, reinforcing division of actions between producers of evidence, and receivers of evidence. This constructs the decision-making process as a highly standardized "activity sequence" (Van Leeuwen and Wodak, 1999: 94), with the chronology suggesting that the Committee's comments and recommendations are made as a direct result of the preceding summary of submissions.

Each quote or summary has a footnote citation to a specific page of a written submission or of the official Hansard transcript of the relevant public hearing (transcription itself also involves entextualization: (Bucholtz, 2007)). In the minority of cases where the submitters are not activated within the body of the paragraph, their responsibility for the content of the paragraph or part thereof is maintained by referencing them in this type of citation. This means that every paragraph in these substantive sections, set out in Figure 1, is assigned to one or more submitter. 
Figure 1: Chapter 3 structure

Introduction paragraph

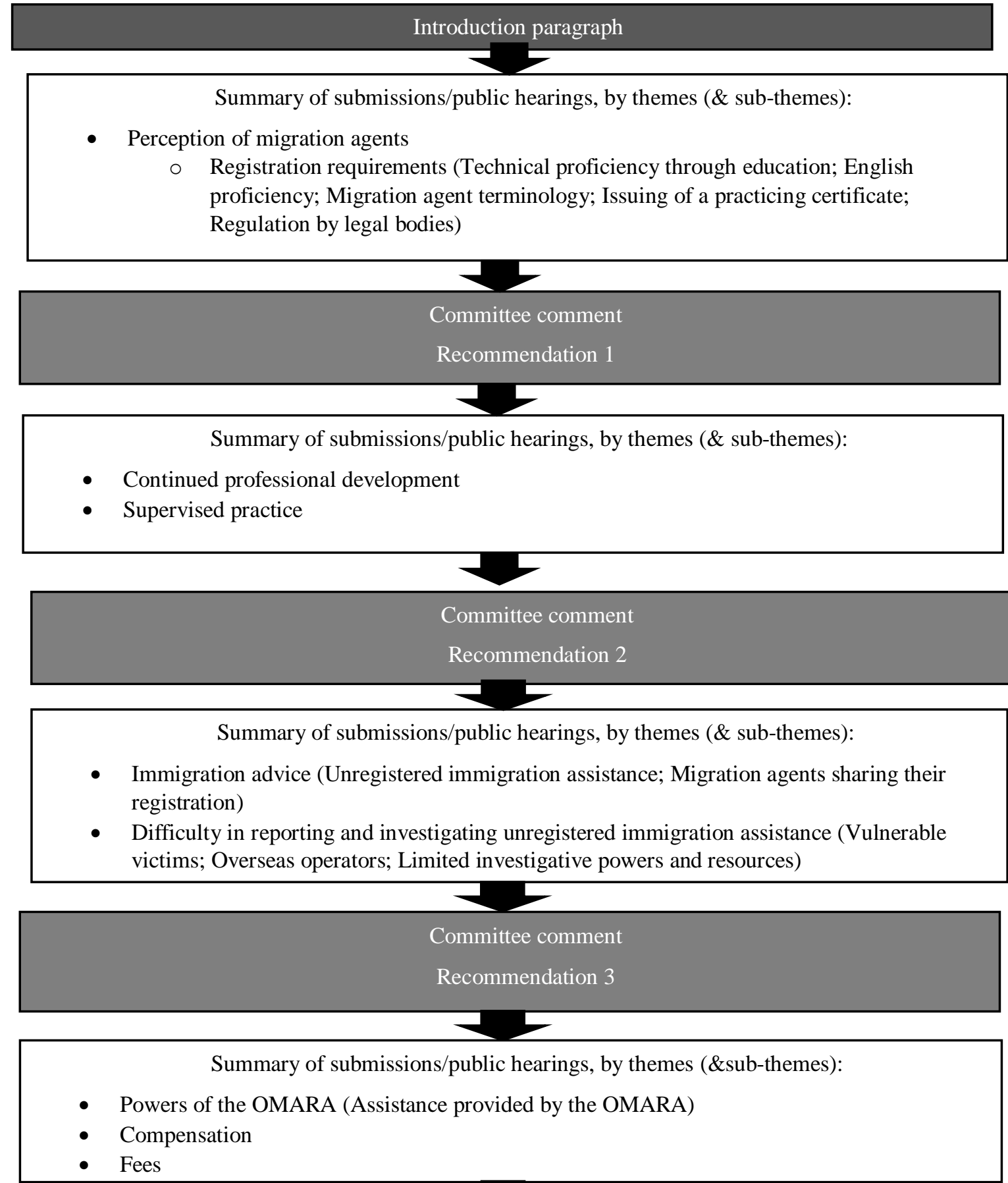

- Compensation

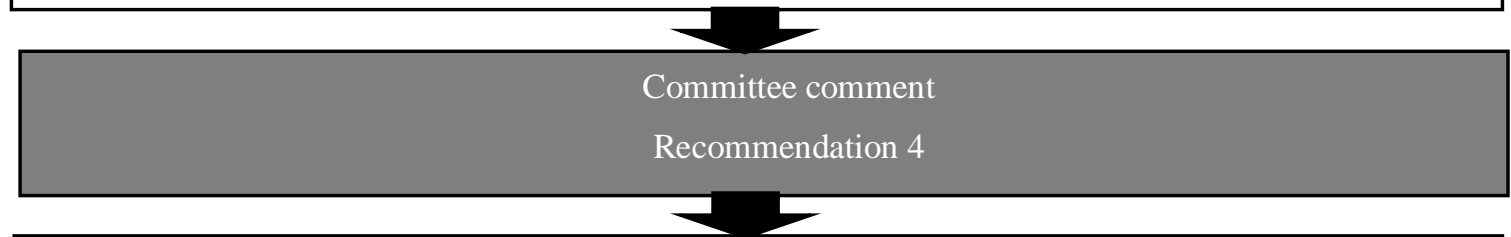

Summary of submissions/public hearings, by themes (\&sub-themes):

- Migration agents providing other services to clients

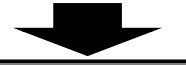

Committee comment 
As set out in Figure 1, in each of the various chapter subsections, the report first summarizes submissions relating to a particular topic or issue, before providing a "Committee comment" and related recommendation(s). These recommendations appear verbatim, with paragraph number cross-references, at the beginning of the report (p. xv), directly after the TORs. In itself, this structure reinforces the assignment of various principals (Goffman, 1981) to these different components of the chapter. This order creates the impression of logic and boundedness: the submitters said these things, in response the Committee comments this, and therefore recommends this and this.

The framing choices in Chapter 3 and throughout the report suggest that the collection and presentation of stakeholder submissions is a legitimate fact-finding exercise, while limiting the report-writers' and Committee's responsibility for any opinions or arguments presented (controversial or otherwise). In this way, similar to the lawyers in Maryns' (2013) study, the report writers can present themselves "as mere animators of the information conveyed" and "obscure the way in which they are themselves deeply implicated in the meaning-making process" (Maryns, 2013: 121). Emphasising or maximising "intertexual gaps" in this way is thus a discursive strategy to perform objectivity and assign responsibility to the person cited (see Briggs and Bauman, 1992: 151).

In the context of conducting an inquiry like this one, the strategies described above act to foreground and emphasise the inquiry's public participatory processes and suggest reliance on external "evidence" as the basis for justifying the conclusions reached. Activating and objectifying "evidence" presents it as stable and static across time, space and texts. Thus, fragments of this evidence can be cut from their origins and placed into the inquiry report without affecting meaning. However, the next section contests this framing by exploring how meaning is indeed transformed through the varying ways the submitters' texts travel to and within the report.

\section{From submissions to report: Traveling discourses about migration practice and its regulation}

The previous section explored how the report represents the inquiry process, finding that submitters are presented as creators of evidence, which in turn determines Committee decisionmaking. This section therefore takes up this presentation, critically examining how submitters' arguments travel and are transformed within report Chapter 3. It first explores the discursive 
strategy of aggregation and its effects on the value and weight given to particular opinions. It then examines how the report incorporates submissions that raise topics that are not institutionally mandated, demonstrating how these are transformed, minimized or completely excluded.

\subsection{Aggregation}

While much of the initial part of the chapter explicitly cites individual submitters, sometimes general statements are made about common themes, observations or arguments. These summary statements are often in addition to and used to introduce individual submitters' comments on a particular topic. Aggregation, the choice to represent multiple actors together, can add weight to truth claims. Even legislative reform is often rationalized "based on 'what most people consider legitimate"" (Van Leeuwen, 1996: 49), making it perhaps unsurprising that this practice appears within a parliamentary inquiry.

Thirteen paragraphs in Chapter 3 involve various types of aggregation that present apparent trends in beliefs and experiences among the submitters. Some appear as simple pluralities, like "Submitters pointed out a number of challenges..." (3.128) and "Submitters put forward the view that..." (3.142). Others include quantifiers that act to emphasise a particular perspective.

\section{Extract 4}

Many submitters to the inquiry also recommended that newly qualified migration agents undergo a period of supervised practice prior to obtaining a certificate to practice (3.82).

While Extract 4 uses the term "many", in reality only five of the 41 written submissions include a suggestion that a period of supervised practice should be added, with one other suggesting it during a public hearing (Official Committee Hansard, 23 July 2018, p. 22).

Of these submitters, two are lawyers and one is the Law Council of Australia ("LCA", the peak body for the legal profession). All three explicitly link their recommendation to existing equivalent requirements for legal practitioners. One of the remaining two submitters appears to recommend supervised practice, but in a subsequent public hearing, focuses more on the idea of tiered practice based on experience level, without clarifying whether supervised practice periods would be essential to this (Official Committee Hansard, 16 July 2018, p. 30). The fifth submitter to include a suggestion does so briefly, again while recommending tiered practice, stating that "This would be supported by the requirement that those completing a migration agent qualification be required to undergo some form or period of supervised training" (Mark 
Glazbrook, sub. 34). This suggestion could be interpreted as falling within the practical training already offered within the Graduate Diploma program.

It is unlikely that submitters raise the idea of supervised practice spontaneously, even though it is not mentioned in the TORs. Here, intertextuality is relevant beyond the current inquiry: influential texts predating the inquiry influence the submissions. As already noted, the legal practitioner submitters refer explicitly to existing regulations for lawyers. Other submitters refer explicitly to recently-conducted government-commissioned reviews. For example, DHA's submission lists recommendations from the "Hodges Review", which included supervised practice (sub. 6, p. 30), without the DHA stating itself whether it agrees with this (or other) recommendations in that review. Associate Professor Mary Anne Kenny notes a similar recommendation in the "Kendall Review" and lists several reasons why such a recommendation would be difficult to implement (sub. 14, pp. 5-7). Submitters may have also been influenced by LCA's submission, as a broader trend throughout submissions was explicit reactions and references to some of LCA's recommendations, as a particularly powerful actor.

While the report lists both specific examples for and against the recommendation, and thus creates the impression of balancing both sides, it does not specify that the participants it quotes in favour are the only ones who make this recommendation. Therefore, it is not clear that the "many submitters" described actually means five written submissions and one hearing participant. Further, it does not mention the approximately 30 submitters who made no recommendation regarding supervised practice. Finally, while the report cites recommendations for and against a period of supervised practice, aggregation is used only to represent the "for" position. Based on this presentation, the Committee recommends introducing a supervision period (Recommendation 2).

\subsection{Topic control, transformation and exclusion}

That not all parts of texts and their meanings travel as well as others is perhaps most clearly demonstrated in instances where submitters try to introduce topics or issues that fall outside the TORs and the TORs' underlying discourses of RMA incompetency and criminality. In some cases, this results in fragments of submissions being cited out of context, or only one example (out of multiple similar submissions) being included, or recommendations and observations being excluded completely. Below are two examples of submitters attempting to introduce issues that are not set out in the TORs, both of which point to systemic or structural factors. The first relates to government funding of immigration assistance and the second relates to law, procedure and immigration decision-maker practices. In each example, 
submitters' original arguments are transformed, demonstrating that texts' trajectories depend on how well they fit within institutionally-preferred topics and discourses, and that "evidence" is not static or produced in isolation by submitters alone.

\section{Government funding of immigration assistance}

Three submitters raise the scarcity of government funding for immigration assistance, even though it is not addressed in the TORs. Previously, government funding of an Immigration Advice and Assistance Scheme (IAAAS) enabled particular applicants, including asylum seekers, or refugees seeking to sponsor family members to join them in Australia, to access free assistance. However, recent governments ended this program and drastically cut funding for this type of assistance. Criticisms of these cuts have been widespread among those who work with these groups (Smith-Khan, 2020, AOP).

While the TORs do not include this funding issue, submitters introduce it in response to terms that are included, such as: "Evidence of the volumes and patterns of unregistered migration agents...providing unlawful immigration services in Australia" (Report, p. xiii), demonstrating creative strategies to navigate the inquiry's constraints. However, their success in subverting control over topic is limited. In the whole report, only one reference is made to government funding, citing only one submission (para. 3.122). Even then, the original text is reduced into a short, dot-point summary. Table 1 sets this out: the underlined text shows fragments that are reproduced from the original into the report summary.

Table 1: Comparison of Submission 13 and Report texts

\begin{tabular}{|c|c|}
\hline Original submission text & Report text \\
\hline $\begin{array}{l}\text { 14. The Humanitarian Group considers that } \\
\text { unregistered and unqualified assistance, in the various } \\
\text { forms that it takes, impacts disproportionately on } \\
\text { disadvantaged and vulnerable visa applicants, } \\
\text { proposers and sponsors. } \\
\text { 15. The removal of funding under the Immigration } \\
\text { Advice and Application Assistance Scheme (IAAAS) } \\
\text { for family reunion assistance has placed a heavy } \\
\text { burden on people from refugee or refugee-like } \\
\text { backgrounds who wish to sponsor or propose family } \\
\text { members to come to Australia but cannot access the } \\
\text { funds required to pay a commercial registered } \\
\text { migration agent. Often these people are those who are } \\
\text { least capable of preparing visa applications } \\
\text { themselves, due to weak English language or literacy } \\
\text { skills. Yet these are people whose family members } \\
\text { overseas are enduring extremely difficult conditions. } \\
\text { The reduced scope of this funding in other areas has a }\end{array}$ & 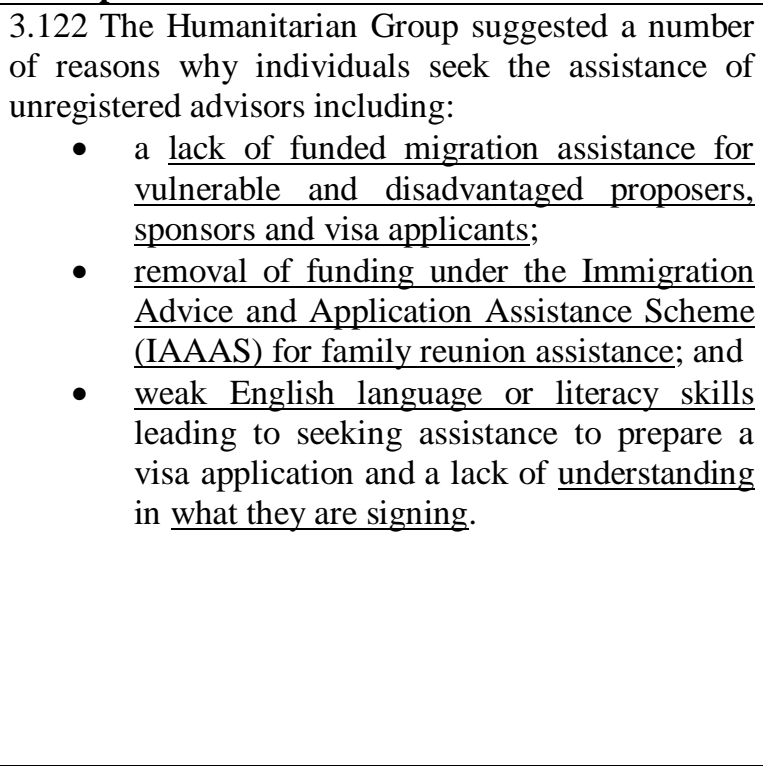 \\
\hline
\end{tabular}


similar impact on clients who are onshore and seeking advice about visa options.

16. These circumstances combine to push such clients towards unregistered assistance in relation to preparing applications or other documents. Often this comes from family or friends in Australia who have only somewhat better English or literacy than the person seeking to apply, sponsor or propose, and who have very poor knowledge of Australian migration law. Arrangements such as these can be lawful, provided no fee is charged. However, the visa applicant/sponsor/proposer is generally incapable of checking the visa application forms and other documents in English and merely signs the forms without understanding what they are signing. Any errors made by people providing well-intentioned help are then attributed to the applicant/sponsor/proposer, whether these arose from mistranslations, misunderstandings or simply human error. The Humanitarian Group has seen hundreds of applications refused in such scenarios.

17. The lack of funded migration assistance for vulnerable and disadvantaged proposers, sponsors and visa applicants also contributes to the problem of unregistered agents.

18. The Humanitarian Group believes it is essential that funding for family reunion applications is reinstated in order to protect people from refugee and refugee-like backgrounds who to be reunited with their close family members.

Even where direct quotes from submissions are embedded in the report, decontextualizing short fragments from the original text, and re-contextualizing them within a sub-section of the report whose main focus is different, alters original meaning. In Table 1, what does not travel is an in-depth explanation of the complex structural factors leading people to seek help from unqualified family and friends, or potentially from other unregistered individuals. These explanations helped justify the strong conclusion, reached in paragraph 18 , that reinstating funding for assistance with family reunion visas is "essential". Nor does the focus on wellmeaning unregistered assistance travel to the report: its inclusion would contradict the TORs' and Foreword's emphasis on unethical and illegal practice, which supports recommending increased powers to police this behaviour.

Table 2 demonstrates how the Refugee Council of Australia's (RCOA) submission is similarly embedded in short fragments, resulting in what appears as a reflection on good and bad RMAs. 


\begin{tabular}{|c|c|}
\hline Original submission text & Report text \\
\hline $\begin{array}{l}\text { Migration agents play a vital role in assisting refugees } \\
\text { and people seeking asylum gain protection and reunite } \\
\text { with separated family members. Often, their support } \\
\text { can mean life or death for a person or their loved ones. } \\
\text { However, there has been a marked decrease in the } \\
\text { funding available for migration agents to provide this } \\
\text { vital assistance. This has forced people who cannot } \\
\text { afford a migration agent to rely on family and } \\
\text { community members to assist them with their visa } \\
\text { applications, resulting in incomplete or inadequate } \\
\text { application. } \\
\text { Further, the desperation of people to seek protection } \\
\text { in Australia, or bring their family member to } \\
\text { Australia, has also pushed people to fall into the hands } \\
\text { of unscrupulous migration agents. These agents may } \\
\text { offer to fast-track a visa application or provide support } \\
\text { where they have no power to make these decisions. } \\
\text { Further, private migration agents who are not } \\
\text { experienced in refugee law may provide substandard } \\
\text { advice, leading to often terrible consequences. } \\
\text { The key way to address the unethical practice of } \\
\text { migration agents and to stop people resorting to using } \\
\text { friends and family to complete their applications is to } \\
\text { adequately fund free, expert migration advice. } \\
\text { Further, the powers of the Office of the Migration } \\
\text { Agents Registration Agency (OMARA) must be } \\
\text { increased to better deal with unscrupulous agents, } \\
\text { including the power to recover funds from unethical } \\
\text { practitioners. This will go a long way in addressing } \\
\text { some of the serious concerns held by refugee } \\
\text { communities and the organisations that support them. } \\
\text { a. } \\
3.1 \text { As mentioned, RCOA has heard numerous } \\
\text { examples of unethical practice from migration agents. } \\
\text { However, the current complaints process within the } \\
\text { Office of the Migration Agents Registration Authority } \\
\text { (OMARA), and the ability to receive redress is } \\
\text { severely limited. }\end{array}$ & $\begin{array}{l}\text { 3.3 The Refugee Council of Australia (RCA) } \\
\text { commented on the vital role migration agents played, } \\
\text { particularly assisting refugees and asylum seekers: } \\
\text { Migration agents play a vital role in assisting } \\
\text { refugees and people seeking asylum gain } \\
\text { protection and reunite with separated family } \\
\text { members. Often, their support can mean life or } \\
\text { death for a person or their loved ones. } \\
\text { 3.4 Conversely, the RCA commented that they had } \\
\text { 'heard numerous examples of unethical practice from } \\
\text { migration agents.' }\end{array}$ \\
\hline
\end{tabular}

This is a troubling transformation of the original, in which meaning is starkly manipulated and key arguments are prevented from travelling at all. Crucially, the report removes arguments relating to government-funded migration assistance for asylum seekers and refugees. RCOA uses these arguments to support its recommendations that previous funding should be restored (sub. 4, p. 3). The report does not acknowledge these concerns or recommendations and again 
removes mentions of people seeking assistance from "friends and family" (and their reasons for this).

Finally and importantly, the Migration Institute of Australia (MIA), the peak professional body for RMAs, and the most cited stakeholder in Chapter 3 (30 paragraphs), and the one with the most substantial submission (80 pages), also recommends "funding be increased for notfor-profit migration advice providers to provide immigration advice and assistance to applicants from migrant communities" (sub. 15, p. 59). Despite citing MIA's observations regarding unregistered assistance (para 3.121), and later summarising their recommendations "aimed at combating unregistered practice" (para 3.147), the report does not mention this funding recommendation. Therefore, unlike the supervised practice recommendation, which is presented as being recommended by "many submitters" and accompanied by citations from each individual submission in favour, the need to reinstate or increase government funding of immigration assistance is presented as being suggested by only one submitter - and then only very briefly. This is despite the inquiry's claimed interest in addressing the vulnerability of some migrants, and the likely role limiting free assistance has in exacerbating this vulnerability.

The focus in these submissions on reliance on presumably well-meaning family and friends to help with applications is simply excluded altogether, despite a purported interest in combatting unregistered individuals providing migration assistance. Challenges to the inquiry's emphasis on unethical or criminal practice extended beyond this particular topic, however, emerging with the introduction of other structural issues.

\section{Law, procedures and practices}

Other themes raised in submissions but missing from the report include the complexity of the migration process and rapid-changing rules; lack of fairness related to some registration requirements; DHA staffing levels, turnover and inconsistent and opaque practices; and the accessibility of information and processes. The only inclusion of these concerns in the report is one fragment included in the sub-section entitled "Perception of migration agents":

\section{Extract 5}

3.12 Ms Marianne Dickie (private capacity) acknowledged that migration agents were not perfect but believed that individuals who had engaged a migration agent were victims of a complex migration process rather than unethical behaviour:

While I acknowledge that agents are not perfect, it is my experience that constituents who have sought assistance from their parliamentarians are not the victims of unethical migration agents. Instead, they are 
victims of the complexity of the migration process, poor decision making, lack of communication from the Department [of Home Affairs] and/or their own decisions regarding their options.

Other submissions highlight similar concerns, challenging institutional emphasis on practitioner competency and language proficiency (see similar critical exploration in SmithKhan, forthcoming), but these do not "travel" into the report at all. For example, Dr Anthony Pun argues against LCA's recommendation of raising the IELTS (English test) score required for registration:

\section{Extract 6}

The entry level of 7.5 (IELT) is unrealistically high. This requirement is unfair because it is not the same playing field when primary decision maker in the Department do not have to show that high level of English language competence (sub. 25, p. 1).

Marianne Dickie's submission is perhaps the most strongly focused on the structural pressures on RMAs, including a whole section entitled "The current situation facing the profession":

\section{Extract 7}

The profession is now at a stage where migration agents are finding it is impossible to act with surety in many areas of migration law. The rapid changes to legislation and policy have resulted in an inability to provide long term advice to clients with confidence. Decision making by the delegates within the Department of Home Affairs also appears to be in crisis. Whilst this may be due to a shortage of staff in the Department, decision makers (particularly in offshore locations) are increasingly acting in ways that confound agents and clients. Low integrity decisions are increasing. Applications can languish for months and years without a case officer assigned to assist. Agents who have been working successfully with the Department for twenty years to achieve client outcomes are openly discussing leaving the profession, due to the nature of their interactions with departmental staff (sub. 20, p. 8).

This approach resists the limits created by the inquiry's TORs, choosing instead to foreground what Dickie considers more pressing concerns.

The Asylum Seekers Resource Centre (ASRC) raises similar concerns, again not completely following the TORs. Their first concern, similar to Dickie, relates to the complexity and evolving nature of migration law:

\section{Extract 8}

1. It is important to note that migration law is one of the most complex and fast changing areas of law. The level of technical difficulty in advising on such voluminous and complicated laws makes the job of migration agents and lawyers alike, inherently very difficult. Even though we focus mainly on one area of migration law, we find it challenging enough to keep up with the constantly shifting laws, regulations, policies and court judgments that are relevant to our work. Simplification of migration law would help reduce the scope for error by migration agents and lawyers alike. It would also make the laws more 
comprehensible and accessible to members of the public, and most importantly to applicants, thus making them less dependent on migration agents, better able to make informed decisions about the conduct of their matters, and more empowered to participate in visa application processes (sub. 10, p. 1).

Responding to the TOR regarding disciplinary processes, ASRC adds concerns that also focus on Departmental practices and mechanisms. Particularly, they point to "the culture and approach of the Department to impugn the credibility of applicants wherever possible, and often unreasonably so". They offer this as a reason why clients would be reluctant to complain to DHA if their agent included incorrect information in their application, since "Decision makers often make adverse credibility findings against individuals in this situation, and such findings do greatly increase the likelihood of an application being rejected" (p. 3). They underline structural and institutional cultural factors to emphasise the reasons for this reluctance:

\section{Extract 9}

Given the information sharing arrangements between sections within the Department of Home Affairs (as well as between the Department and other agencies falling under the Home Affairs Portfolio) and the enormous effort by the Department in uncovering any possible inconsistencies in protection visa applications, we find it difficult to assure clients that they can safely lodge complaints against unregistered agents without risk of it potentially having negative repercussions for their case. Unfortunately, it is our experience that applicants really do need to exercise a great deal of caution regarding any information they provide, or interactions they have, with the Department (sub. 10, pp. 3$4)$.

ASRC also raises concerns about the accessibility of the online complaint form provided by DHA for reporting issues with RMAs, which "is not presented in very accessible user-friendly language or format":

\section{Extract 10}

The entry point to the form is headed 'Border Watch - report something suspicious'. The complainant then needs to select the table titled 'report suspicious immigration activity' and provide details of the 'offence' allegedly committed from a drop-down table of other offences. Notably, the form is also only available in English. These all present significant access issues, especially for vulnerable complainants (sub. 10, p. 4).

Criminality discourse is clear here too, reflecting the inquiry discourse. The form's, and the placement of this complaints process alongside reporting other possible "offences" related to suspicious immigration activity also suggests the discursive alignment of "suspicious" migration practitioners with "suspicious" migrants: their practices and traits are grouped 
together procedurally. This conceptualization is also reflected in the report foreword, which presents migrants as "circumventing" laws and "using" asylum processes to stay in Australia. They are described as being part of an "orchestrated scam" by "unscrupulous individuals", "organized crime and illegitimate labour hire companies", albeit while also framing migrant workers as vulnerable to exploitation (pp. 7-8). Therefore, discourses of criminality apply to both practitioners and migrants and pervade institutional discourse beyond the inquiry.

The submissions described in this section seek to draw attention to the legal and institutional context in which RMAs work and their clients apply for visas, making observations and suggestions relating to everything from the complexity of law, through the design and accessibility of forms, to the changing staffing and communication channels within the Department. Yet, as is the case with government funding cuts, these issues are largely invisible in the report, just as they are absent in the TORs.

The analysis in the previous section demonstrated how submitters are presented as active participants in the inquiry process, as primary speakers and creators of the "evidence" presented in the report. The analysis in this section has contested this framing by exploring textual travel, and how (parts of) submissions are organized, cited and described in the report and demonstrating that not all arguments or issues travel successfully or retain their initiallyintended meaning.

\section{Control over discourse and the 'presentation' of evidence}

The above analysis sought to demonstrate how the report presents the inquiry process as one in which evidence is obtained from stakeholders and used to arrive at a set of conclusions. The idea that texts are extractable in this way is "an assumption that still prevails in legal-procedural contexts" (Maryns, 2013: 107). However, emerging from this analysis are examples of some ways in which the "evidence" attributed to these actors is transformed - or excluded - from the report.

Further, as demonstrated above, the practice of collecting, extracting and embedding fragments of texts within an inquiry report has other effects. Assigning authorship and responsibility for most of the text to the submitters indexes their agency throughout the inquiry process. Assigning passive, receptive roles to the Committee likewise acts to limit its responsibility for the creation of problems, evidence or opinions. Applying genre norms in the presentation of these summaries, comments and recommendations adds legitimacy and 
suggests that the ideas expressed within them are produced objectively (Briggs and Bauman, 1992).

However, in reality, there is ample scope for variety in what is included in the report, and how, and there are large and obvious power asymmetries throughout the inquiry process and within the report's creation. The various inquiry participants obviously have unequal power in deciding to conduct an inquiry in the first place, and then which topics should be explored within it. The inquiry's TORs dictate the "social problems" needing policy responses long before submitters have the opportunity to participate. At the end of the inquiry, these TORs remain the problems to which answers are proposed.

Section 5 identified some attempts to shift beyond the TORs. Sometimes submitters introduce novel concerns by connecting them to a particular TOR, therefore attempting for their topic introduction to respect the mandated focus. Others introduce issues in the submission using their own structure, without reference to individual TORs, rather relating them to RMA experiences, education and practice more generally. However, as seen above, how (much of) these concerns travel into the report is out of submitters' control. Where their concerns clash with dominant discourses of RMA incompetency and criminality, they make little to no appearance, and do not lead to any particular recommendations. This is evident in the case of submitters recommending increased government funding of free migration assistance, and in the various criticisms of migration law, the immigration department, its processes and its staff's attitudes, competencies and practices.

Further, this article has not examined one type of "evidence" collected, because it was impossible to do so: the inquiry included an online questionnaire for clients of migration or education agents "to understand the individual experiences of a broad range of people", and another for migration agents "to put forward their views on the current migration agent regulatory regime" (Parliament of Australia, 2018a). While these were conducted, the report does not mention the questionnaires and or their results at all, nor have the responses been published elsewhere. The (empty) questionnaire forms themselves are equally unavailable for public scrutiny (email correspondence, James Bunce, Inquiry Secretary, 22 January 2020). Their absence from the report makes it impossible to know how or whether the questionnaire responses were taken into consideration in reaching conclusions, or whether these individual experiences and opinions coincided with the TORs, Committee comments or recommendations. 
Submitters are not insensible to the problematic discourses that exist within and beyond the inquiry and its report, and the role inquiries like this have in promulgating and entrenching these dominant discourses. In her submission, Dickie addresses this explicitly:

Extract 14

I would like to voice my disappointment in yet another inquiry that includes the education and regulation of agents. This is the latest in a series of reviews and it comes at a time when many of the new educational and registration requirements recommended in the Kendall Review have yet to be implemented. Others such as English proficiency have been addressed previously within the legislation and the thresholds for post graduate entry into university. The new regime exempting lawyers from registration is expected to begin in November this year. The efficacy and impact of these changes will not be able to be assessed for at least two years. Therefore, an examination of the educational threshold for registration as a migration agent appears to be preemptive.

Stakeholder concern regarding the adequacy of qualifications for accreditation of agents has been consistent over the past twenty years. It has been fuelled both by the increasingly adversarial attitude the Department has towards agents and the long-term anxiety of the legal profession towards dual regulation. Public discussion of unethical practices of migration agents often ignores the distinction between registered migration agents, education agents, RMA/lawyers and unregistered agents. This conflation of a range of people who may be operating within the migration advice space results in an inability to focus coherently on the profession of migration agents (sub. 20, p. 2).

Dickie expresses a concern with the very practice of conducting the inquiry and asking the particular questions it asks (through the TORs). She points out the impracticality of doing so at this point in time, when other recommendations have only recently been implemented. She also criticizes both the repetitive nature of such processes and responses, and their appropriateness. Finally, she puts the spotlight on the motivations of the dominant actors, which have prompted these concerns and the resulting processes. She thus provides a metacommentary and criticism of the social practice of conducting these inquiries and the discourses which justify them.

However, it is clear that such challenges to dominant discourses are constrained - whether they relate to issues around migration practice regulation or directly critique the inquiry process itself. This is because of the very unequal power over discourse production in the inquiry process, from its inception, at the point of developing TORs which dictate its focus, through to drafting the report, and the comments, recommendations and Foreword therein.

The treatment of Dickie's criticisms is a perfect case in point. Like the examples in section 5 , they travel poorly, resulting in a deceptively contradictory meaning: 


\section{Extract 15}

Ms Marianne Dickie noted that concern over the 'adequacy of qualifications for accreditation of agents has been consistent over the past twenty years' (para. 3.22).

The decontextualization of this phrase effectively subverts Dickie's criticisms of repetitive inquiries and the problematic motivations behind them. Her remaining concerns are simply excluded. Further, while another submission's similar criticisms over the poor timing of the inquiry are mentioned (see para. 3.24, citing sub. 14 (Mary Anne Kenny)), the Committee ironically transforms this criticism into a justification for its first recommendation - to conduct yet another review to evaluate the appropriateness of the same registration requirements examined in the current inquiry (this has since been completed, in 2020).

The pertinent "social problems" have long been decided and submitters are guided towards discussing these only, and in doing so their contributions serve to legitimate the existence of and focus on these problems (see similar concerns in Bacchi, 2018). While they may have specialist knowledge, submitters have limited control over its "production, circulation and reception" (Briggs, 2005: 274) and no say in how their arguments are received, transformed and ultimately how they contribute towards the Committee reaching certain recommendations. Even where submissions openly attempt to criticize the TORs or the inquiry itself, their arguments can simply be excluded from the report, or even be transformed to actually justify another review process. This demonstrates not only the unequal discursive resources participants have to contest issues related to migration practice. There is also unequal control over discourse about the legitimacy of the inquiry process itself. Dominant discourses about participating in and conducting inquiries are favoured to reinforce the legitimacy of these processes and support their future use, thus preserving control over future discussions of migration practice and its regulation.

\section{Conclusion}

This article has critically examined the trajectories of texts and discourses within a parliamentary inquiry to interrogate the participatory and evidence-gathering nature of the process. It thus contributes a new methodological approach to support criticisms made in existing research regarding evidence-based policymaking (eg Van Toorn and Dowse, 2016).

The examination has demonstrated the extensively unequal powers of the inquiry participants. Committee members have control over everything from the initial decision to 
conduct an inquiry, the TORs within it, whether or not to hold public hearings, whom to invite, whether or not to publish written submissions and other evidence, the structure and content of the report. Ultimately, through their legislative powers alongside their fellow MPs and senators, they also have the power to create laws on the basis of the Committee's recommendations, or not. Further, through the report, they largely retain power over the discourse about discourse production in this setting: submitters can be presented as having agency and being the primary creators of "evidence" upon which policy recommendations are made, regardless of how the report incorporates this evidence, thus increasing the legitimacy of these processes.

This makes inquiries a powerful discursive resource to justify the making of laws affecting whole societies, or segments within them. In the case of the above inquiry, from beginning to end, institutional discourses question the integrity and competency of RMAs, focusing on their individual deficiencies, all while ignoring the structural limitations within which they work and within which would-be migrants apply for visas. It is little wonder then that RMAs would report an "increasingly adversarial attitude" or worsening communication barriers in their interactions with immigration officials. However, RMAs are not in a position to control inquiry discourse, nor to effectively challenge the inquiry's legitimacy. This means these issues go unaddressed, and RMAs themselves continue to be held up as unsolved policy problems. It is thus essential that advocates, organizations and commentators representing the interests of RMAs and migrants continue to resist and challenge such dominant discourses, both within and beyond institutional confines.

\section{References}

Bacchi C. (2019) Drug Problematizations and Politics: Deploying a poststructural analytic strategy. Contemporary Drug Problems 45: 3-14.

Briggs CL. (2005) Communicability, Racial Disourse, and Disease. Annual Review of Anthropology 34: 269-291.

Briggs CL and Bauman R. (1992) Genre, intertextuality and social power. Journal of Linguistic Anthropology 2: 131-172.

Bucholtz M. (2007) Variation in transcription. Discourse Studies 9: 784-808.

Eades D. (2012) The social consequences of language ideologies in courtroom crossexamination. Language in Society 41: 471-497.

Fairclough N. (2001) Critical discourse analysis as a method in social scientific research. In: Wodak R and Meyere M (eds) Methods of Critical Discourse Analysis. London: SAGE, 121-138.

Goffman E. (1981) Forms of Talk, Pennsylvania: University of Pennsylvania Press. 
Heffer C, Conley J and Rock F. (2013) Legal-law communication: Textual travels in the law. Oxford University Press.

Johnson A. (2013) Embedding polic interviews in the prosecution case in the Shipman Trial. In: Heffer C, Conley J and Rock F (eds) Legal-lay communication: Textual travels in law. Oxford University Press, 147-167.

Khan M. (2019) Contested Ground: Network governance in Australia's migration industry. International Migration 57: 295.

Maryns K. (2013) 'Theatricks' in the courtroom. In: Heffer C, Conley J and Rock F (eds) Legallay communication: Textual travels in the law. Oxford University Press, 107-125.

Park JS-Y and Bucholtz M. (2009) Introduction: Public transcripts: entextualization and linguistic representation in institutional contexts. Text \& Talk 29: 485-502.

Parliament of Australia. (2018a) About this inquiry. Available at: https://www.aph.gov.au/Parliamentary_Business/Committees/Joint/Migration/Migrati onagentregulatio.

Parliament of Australia. (2018b) Terms of Reference. Available at: https://www.aph.gov.au/Parliamentary_Business/Committees/Joint/Migration/Migrati onagentregulatio/Terms_of_Reference.

Parliament of Australia. (2021) Completed inquiries. Available at: https://www.aph.gov.au/Parliamentary_Business/Committees/Joint/Migration/Comple ted_inquiries.

Rock F, Heffer C and Conley J. (2013) Textual travel in legal-lay communication. In: Heffer $\mathrm{C}$, Conley J and Rock F (eds) Legal-lay communication: Textual travels in the law. Oxford University Press, 3-32.

Smith-Khan L. (2017a) Different in the same way?: Language, diversity and refugee credibility. International Journal of Refugee Law 29: 389-416.

Smith-Khan L. (2017b) Telling stories: Credibility and the representation of social actors in Australian asylum appeals. Discourse \& Society 28: 512-534.

Smith-Khan L. (2019a) Communicative resources and credibility in public discourse on refugees. Language in Society 48: 403-427.

Smith-Khan L. (2019b) Debating credibility: Refugees and rape in the media. Australia Review of Applied Linguistics 42: 4-36.

Smith-Khan L. (2019c) Why refugee visa credibility assessments lack credibility: a critical discourse analysis. Griffith Law Review 28: 406-430.

Smith-Khan L. (2020) Migration practitioners' roles in communicating credible refugee claims. Alternative Law Journal 45: 119-124.

Smith-Khan L. (AOP) "I try not to be dominant, but I'm a lawyer!": Advisor resources, context and refugee credibility. Journal of Refugee Studies https://doi.org/10.1093/jrs/feaa102.

Smith-Khan L. (forthcoming) "Common language" and proficiency tests: A critical examination of registration requirements for Australian Registered Migration Agents. Griffith Law Review.

Van Dijk TA. (2008) Discourse and Power, Basingstoke: Palgrave Macmillan.

Van Leeuwen T. (1996) The representation of social actors. In: Caldas-Coulthard CR and Coulthard M (eds) Texts and Practices: Readings in critical discourse analysis. London: Routledge, 32-70.

Van Leeuwen T. (2007) Legitimation in discourse and communication. Discourse \& Communication 1: 91-112.

Van Leeuwen T and Wodak R. (1999) Legitimizing immigration control: a discourse-historical analysis. Discourse Studies 1: 83-118. 
Van Toorn G and Dowse L. (2016) Policy claims and problem frames: A cross-case comparison of evidence-based policy in an Australian context. Evidence \& Policy 12: $9-24$. 